\title{
Field independence/dependence, sex, and water levels
}

\author{
JEROME H. BLUE, JOHN A. COOPER, and SHERMAN ROSS \\ Howard University, Washington, D.C. 20059
}

\begin{abstract}
College students (333 women and 174 men) were tested to see if they knew that the surface of still water is invariantly horizontal. Participants were assigned randomly to one of five different groups. These groups had different response outlines and explanations of the topic in question. Results showed that women did not make more errors than men in all experimental groups. This finding suggests that women are not necessarily field dependent, as some studies report. Depending upon the amount of instruction and type of response outline, no difference between men and women on this test of cognitive capacity was found.
\end{abstract}

Cognitive developmentalists such as Goodenough and Eagle (1963), Witkin, Dyk, Faterson, Goodenough, and Karp (1962), Witkin, Lewis, Hertzman, Machover, Meissner, and Wapner (1954), and others have been concerned with field independence/dependence. Men have been reported to be more field independent, and women, more field dependent. Witkin et al. (1954, 1962) have developed several tests to illustrate this relationship. The rod and frame test and embedded figures test, which involve disembedding items from organized perceptual contexts, have been used to determine field dependence/independence. It has also been indicated that games played by boys facilitate the differences seen on various cognitive tests (Sherman, 1967). Findings such as these have led to the notion that men are more analytical in their thought processes than women, who are more global (Witkin, Moore, Goodenough, \& Cox, 1977). Witkin, Moore, Oltman, Goodenough, and Cox (1977) also mentioned that when internal referents are less available, for example with field-dependent people, attention is usually given to dominant aspects of the stimulus field.

One test of this relationship is to determine if participants know that the surface of still water is always horizontal. Thomas, Jamison, and Hummel (1973) designed a procedure to facilitate the acquisition of the underlying principle. The experimental group was given a pretest, questioned about the principle, and then tested again. The control group was asked questions first and then tested with the special apparatus. Women were allowed to participate in the study only if they did not meet a precriterion level of performance. The control group of men was unselected, only questioned and then tested. The apparatus consisted of two bottles, placed on separate rotatable disks, so that the bottles could be oriented in positions that ranged from 1:00 through

Requests for reprints should be made to Sherman Ross, Department of Psychology, Howard University, Washington, D.C. 20059
11:00 positions. One bottle, on the left-hand side of the subject during testing, was half full of water and was designated as the model. There was a removable cover that could be placed over the model. The experimental bottle was on the right-hand side of the subject and had a rotatable disk within. The results showed that when the model was not covered, participants made accurate waterline adjustments. A large number of errors were found when the participants made adjustments without being able to see the model. Women failed to acquire the concept if they did not already know that the surface of still water is always horizontal. Thomas et al. (1973) concluded that the participants who performed poorly did so because they lacked the conceptualization of the problem. Perper and Chase (1974) criticized the Thomas et al. study by saying that the control and experimental groups were treated differently. Control group members received cues in the form of leading questions about the purpose of the test before they could generate their own hypotheses and make any errors with the apparatus. The experimental participants were not asked leading questions and, consequently, received no cues about the purpose of the test. This difference was not viewed as being insignificant when the effect of preknowledge on test performance was tested. Another investigator (Munsinger, 1974) was concerned with whether or not the Thomas et al. results were due to measurement artifacts; Munsinger reported results contrary to those of Thomas et al. (1973).

Munsinger (1974) used different measuring devices to see whether or not women knew that the surface of still water is always horizontal. A water jar was angled at $1: 00,2: 00,4: 00,5: 00$, and $6: 00$ positions. The participants had to draw the water levels on paper or choose the correct water level from among three alternatives and state the principles in question. Men and women in this study knew that the surface of still water is invariantly horizontal. Sex differences were not found. It seems reasonable to say that women may not be field dependent on tests such as the ones used to determine 
whether the surface of still water is always horizontal.

The present study is concerned with factors that might have produced the differences in the earlier studies. Sophisticated and naive participants, men and women, were used in the experimental and control groups. Three levels of explanation of the underlying principles were given to see if subjects could learn, if they did not already know, that the surface of still water is invariantly horizontal.

\section{METHOD}

\section{Research Participants}

Undergraduate psychology students (333 women and 174 men) at Howard University volunteered to participate. They were assigned randomly to one of five different groups.

\section{Apparatus}

The apparatus consisted of an opaque styrofoam cup (height: $9.2 \mathrm{~cm}$, base diameter: $4.9 \mathrm{~cm}$, top diameter: $8.4 \mathrm{~cm}$ ) half filled with water and a response card $(8.5 \times 21.5 \mathrm{~cm})$. Response cards differed depending upon the experimental group.

All participants in Groups 1 and 2 were given blank cards. Two cups were drawn on the cards of Group 3, as shown in Figure 1. One of these cups was angled 45 deg relative to the other cup, which was in an upright position. No waterline was drawn on these cups, and they appeared empty. Response cards for Group 4 had three cups drawn on them, with corresponding waterlines associated with their $22.5-\mathrm{deg}$, $45-\mathrm{deg}$, or upright positions. Group 5 had cups drawn exactly like Group 3. To minimize position preference, the order of cup presentation from left to right was randomized.

\section{Procedure}

No prior explanation of principles concerned with the fact that the surface of still water is invariantly horizontal was given to Group 1. The experimental session was marked by the presentation of the styrofoam cup. Participants were asked to view the cup, which was half filled with water. While the cup was in

\section{Groups 3 and 5}
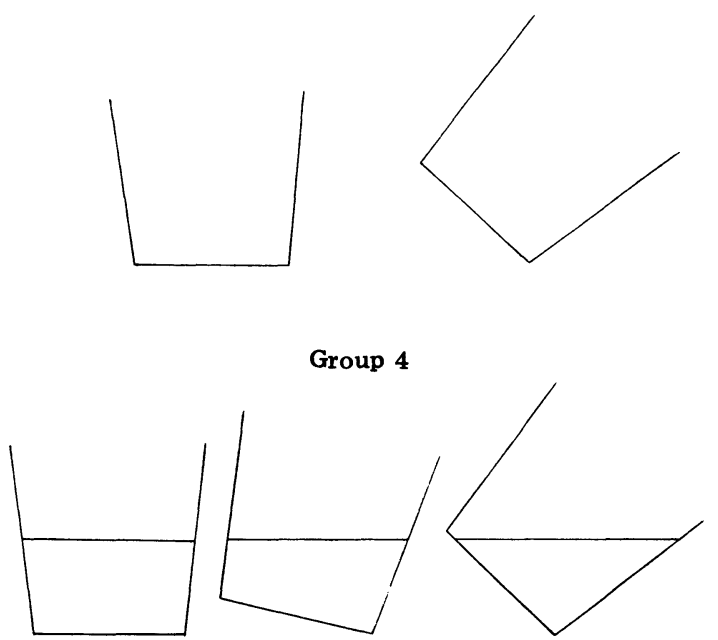

Figure 1. The response cards used by participants assigned to Groups 3, 4, and 5. The other response cards were blank (Groups 1 and 2).
Table 1

Percentages of Correct Responses for Each Group of Subjects

\begin{tabular}{lccccc}
\hline & \multicolumn{5}{c}{ Group } \\
\cline { 2 - 6 } & 1 & 2 & 3 & 4 & 5 \\
\hline Men & 94.19 & 73.5 & 84.01 & 69.8 & 64.40 \\
Women & 32.10 & 43.2 & 34.09 & 78.1 & 69.89 \\
\hline
\end{tabular}

Note-Group 1 received no explanation. Group 2 received a nostructure explanation. Group 3 received a structure explanation. Group 4 received a forced-choice explanation. Group 5 received a special explanation structure.

an upright position, the students were asked to draw the cup and the waterline on the response card. One minute afterwards, the cup was tilted $45 \mathrm{deg}$, and the participants were asked to draw the cup and the waterline once more.

Group 2 differed from Group 1 in that it received a brief explanation about rod and frame tests and tests of embedded figures. This talk served as an explanation of the principles that illustrate conceptual differences between participants on measures of field independence.

Subjects in Group 3 also received an explanation similar to that given to Group 2, but with more structure and detail. Each subject was given a response card with two cups; one was upright, and the other was tilted $45 \mathrm{deg}$. The task was to draw the waterline, which corresponded to the cup's position as presented in front of the class.

A similar explanation was also given to Group 4, in which a forced-choice procedure was used. These participants were asked to place a 1 beside the cup that had a waterline corresponding to the water level in front of the class (an upright position). A 2 was to be placed next to the cup that best depicted the second presentation (45-deg tilt).

A special explanation of the principles involved in this experiment was given to participants in Group 5 before they responded to the sample. Participants were told that there are differences in people in terms of field dependence and field independence. In addition, they were told that the surface of still water is always horizontal. Following these explanations, the procedures of Group 3 were applied.

\section{RESULTS}

The results showed that there was a significant difference between subjects when the five methods of instruction were compared $\left[\chi^{2}(4)=34.58, p<.05\right]$. A $t$ test showed that men had a higher percentage of correct responses than women when all groups were combined $[t(505)=4.38, p<.05]$. Men maintained a significantly higher percentage of correct responses over women in Groups 1, 2, and 3. However, there was no significant difference between men and women in Groups 4 and 5. Table 1 shows the percentage of correct responses for men and women on each set of instructions.

Men in Group 1 were 94\% correct, compared with women, who were $32 \%$ correct. The comparable results for Group 2 were $73 \%$ and $43 \%$, and for Group 3, 84\% and $34 \%$. Only in Groups 4 and 5 did both men and women obtain equivalent correct response percentages. Men in Group 4 had a $70 \%$ level of correct responses, compared with $78 \%$ for women, and Group 5 men had a $64 \%$ level of correct responses, compared with the 
women's $69 \%$. In addition, women in Groups 4 and 5 did better than men, with a difference of $8 \%$ and $6 \%$ in Groups 4 and 5, respectively.

\section{DISCUSSION}

It appears that the method by which participants are tested markedly influences whether or not they know and understand that the surface of still water is invariantly horizontal. Further, the amount of information they receive also has an effect on responses. Men were not different from women across all groups. In fact, women made a lower percentage of errors than men in both Groups 4 and 5 . This finding might lend itself to Witkin, Moore, Oltman, and Goodenough's (1977) suggestion that field-dependent people are interested mostly in readily available referents, whereas field-independent people are more concerned with ideas and abstract principles. Thus, the women participants could have been attentive to cues provided in Groups 4 and 5 (i.e., field dependent), and the men could have been insensitive to these cues in their search for abstract material related to the task. Whatever the reason for women doing better than men in Groups 4 and 5, the results suggest that women can learn the principle that the surface of still water is always horizontal.

Coates (1974) mentioned that field independence is one of the most extensively and thoroughly studied constructs in personality research dealing with cognitive styles. However, the results of this experiment suggest that this characteristic needs to be investigated further, especially using measures without biases. It is possible that developmental processes contribute to the greater field independence of men, but this certainly does not appear to be the case for tests involving the surface of still water. It seems reasonable to test men and women with revised methods or other tests of cognitive capacity. This type of investigation seems even more needed since Coates (1974) mentioned that there are relatively no sex differences in field independence in young children and in older adults. It is possible that men and women do not differ over the life span, since this study and that of Munsinger (1974) found that men and women do not differ in field dependence at the college level.

In conclusion, the results support the notion that women may not be differentially field dependent, and if they are, they readily learn that the surface of still water is invariantly horizontal. This conclusion is in contradiction to that of Thomas et al. (1973) and supports the findings of Munsinger (1974). The results also support the criticisms of Perper and Chase (1974).

\section{REFERENCES}

Coates, S. Sex differences in field independence among preschool children. In R. C. Friedman, R. M. Richart, \& R. L. Van de Wiele (Ed.), Sex differences in behavior. New York: Wiley, 1974.

Goodeneough, D. R., \& Eagle, C. J. A modification of the embedded-figures test for use with young children. Journal of Genetic Psychology, 1963, 103, 67-74.

Munsinger, H. Most college women already know that the surface of still water is always horizontal. American Journal of Psychology, 1974, 87, 717-718.

Perper, T., \& Chase, J. Conceptual deficits in women. Science, 1974, 184, 809-811.

Sherman, J. A. Problem of sex differences in space perception and aspects of intellectual functioning. Psychological Review, 1967, 74, 290-299.

Thomas, H., Jamison, W., \& Hummel, D. D. Observation is insufficient for discovering that the surface of still water is invariantly horizontal. Science, 1973, 181, 173-174.

Witkin, H. A., Dyk, R. B., Faterson, H. F., Goodenough, D. R., \& KARP, S. A. Psychological differentiation: Studies of development. New York: Wiley, 1962.

Witkin, H. A., Lewis, H. B., Hertzman, M., Machover, K., Meissner, P. B., \& Wapner, S. Personality through perception. New York: Harper, 1954.

Witkin, H. A., Moore, C. A., Goodenough, D. R., \& Cox, P. W. Field-dependent and field-independent cognitive styles and their educational implications. Review of Educational Research, 1977, 47, 1-64.

Witkin, H. A., Moore, C. A., Oltman, P. K., Goodenough, D. R., Friedman, F., Owen, D. R., \& Raskin, E. Role of the field-dependent cognitive styles in academic evolution: A longitudinal study. Journal of Educational Psychology, 1977, 69, 197-211.

(Received for publication July 10, 1980.) 